\title{
A Importância do Gerenciamento de Acervos Digitais para Preservação de Documentos Históricos
}

\section{La Importancia de la Gestión de Colecciones Digitales para la Preservación Histórica de Documentos}

\author{
Rafael Rosa da Silva1; Ícaro Vasques Inchauspe²; Carina Marques Milano³; Tatiane Marques \\ de Oliveira ${ }^{4}$. \\ 1rafarosasilva@gmail.com, Universidade Federal do Pampa; ${ }^{2}$ icarovasques@ gmail.com, \\ Universidade Federal do Pampa; ${ }^{3}$ carinamilano@ unipampa.edu.br, Universidade Federal do \\ Pampa; ${ }^{4}$ tatianeoliveira@ unipampa.edu.br, Universidade Federal do Pampa.
}

\begin{abstract}
Resumo
O presente trabalho tem a finalidade de apontar a relevância para mecanismos que façam o gerenciamento de acervos digitalizados, contribuindo para a preservação de documentos históricos que estão armazenados no Instituto Histórico e Geográfico de Jaguarão (IHGJ). Disseminar o conhecimento através das mídias digitais, preservando e proporcionando o acesso a fontes históricas de forma a contribuir na formação da memória e identidade local como base de armazenamento através de bibliotecas digitais.
\end{abstract}

Palavras-Chave: gerenciamento, acervos, bibliotecas digitais, preservação, documentos históricos

\section{Novas mídias e tecnologias de armazenamento}

Com o intuito de facilitar o acesso aos documentos e contribuir em sua preservação de documentos históricos, vários procedimentos foram e ainda são utilizados. De forma, entre as propostas mais recentes, sobrevém a sugestão da digitalização, compreendida como um meio para complementar soluções relacionadas tanto à preservação quanto ao acesso. Pode ser vista como uma maneira de preservação, porque torna possível o acesso ao documento original, liberando apenas para consulta o material digitalizado.

Pensando na forma de assegurar uma longa vida útil para o acervo como um todo, o método mais eficiente, em relação aos custos e aumentar sua longevidade, é prevenir da melhor forma possível a sua danificação. Assim, o planejamento da preservação, não deve ser visto como um elemento novo, mas como um componente das operações e responsabilidades da instituição (SILVA FILHO, 2004).

Arellano (2008) atenta para que a preservação através da digitalização está muito ligada ao espaço cada vez maior, à medida que a rede tecnológica vem se apropriando dos espaços públicos e privados. As sociedades contemporâneas esperam contar com o domínio de recursos digitais para garantir o acesso a digitalização de documentos, e não só a preservação da garantia da informação, mas também como uma forma de facilitar a disseminação de bibliotecas eletrônicas e digitas, tendo como objetivo o gerenciamento de acervos digitais para preservação de documentos históricos como forma de atender necessidades urgentes de uma comunidade especifica, democratizando o acesso a bens simbólicos até então restritos. 


\section{Métodos de análise e abordagem dos documentos históricos}

A metodologia utilizada até o momento foi a identificação de fontes primarias disponíveis, como jornais do Século XIX e XX. Após a identificação foi feito o escaneamento, para depois serem organizados em ordem cronológica e grupos temáticos para serem salvos no formato PDF (Portable Document Format). Logo após os arquivos foram gravados em CD/DVD.

Por fim, os arquivos, já gravados em CD/DVD serão disponibilizados em um repositório online, para que não só a comunidade acadêmica, mas pesquisadores e interessados passam ter acesso às informações contidas nos documentos digitalizados. A escolha do processo de digitalização como mecanismo de preservação da documentação histórica implica na escolha tanto do equipamento onde se realizará a digitalização, como também as questões relacionadas ao gerenciamento do ambiente tecnológico em que se inserem os representantes digitais. Portanto, o processo abrange um gerenciamento aplicado para bibliotecas digitais como repositório de materiais digitalizados, onde contribui por ser uma ferramenta de armazenamento.

\section{Possibilidades acerca da história e memória local}

A digitalização de documentos históricos implica num processo não só tecnológico, pois é de extrema importância que o documento a ser digitalizado seja manuseado com cuidado e cautela, sendo necessário a higienização muitas vezes desse documento. A higienização é um dos procedimentos mais importantes no processo de preservação de documentos, pois a ação dos resíduos que se depositam ao longo do tempo degrada a estrutura do suporte, resultando como consequência à perda de informações importantes do acervo (BELOTTO; CAMARGO, 1996). Até o momento foram digitalizados aproximadamente 100 jornais, entre o século XIX e XX.

Os periódicos digitalizados contém informações locais, regionais, nacionais e internacionais. As informações obtidas através desses documentos vão desde anúncios comerciais do período escravocrata, atividades de fronteira (troca e venda de produtos), informações sobre a coroa portuguesa, $1^{a}$ guerra mundial, e indo ao encontro de conteúdo dos mais diversos vieses como: estudantis, religiosos, poéticos, e políticos através de noticiários sobre o período da ditadura militar. Enfim, esses documentos são a representação materializada da memória, de um contexto brasileiro e jaguarense. Sendo assim, é necessário que sejam estudadas técnicas e alternativas que permitam aumentar a durabilidade e que possa auxiliar na preservação dessa memória (VIEIRA, 2011).

\section{Considerações finais}

Por fim, o processo de digitalização tem um caráter não só de preservação, mas também de importância histórica, tendo em vista que os documentos analisados e posteriormente digitalizados mostram fatos históricos de determinados períodos da cidade de Jaguarão.

Nesse sentido, o gerenciamento desses arquivos ajuda a ampliar as possibilidades para pesquisa, como compreender não só os acontecimentos, mas também problematizá-los.

Para isso, além dessa ferramenta de preservação de documentos históricos, as mídias digitais proporcionam maior acessibilidade e usabilidade dos documentos até então, preservados, facilitando o acesso e informação, trabalhando na perspectiva sobre a memória e 
discutir a identidade local a partir de uma visão mais crítica sobre os conteúdos digitalizados e armazenados.

\section{Referências}

ARELlanO, M. A. Critérios para a digitalização da informação científica. 2008. 354 f. Tese (Doutorado em Ciência da Informação) - Universidade de Brasília, Departamento de Ciência da Informação, Brasília, 2008.

BEllotTo, H. L.; CAMARGO, A. M. A. Dicionário de terminologia arquivística. São Paulo: Associação de Arquivistas Brasileiros, 1996.

SILVA FILHO, J, T, D. Conservação preventiva de acervos bibliográficos. Disponível em: $<$ http://www.forum.ufrj.br/biblioteca/artigo.html> Acesso em: 10 set. 2015.

VIEIRA, L.C.B. Digitalização de Documentos Históricos: uma alternativa para a preservação e disseminação da memória e patrimônio cultural. In: XIV Encontro Regional de Estudantes de Biblioteconomia, Documentação, Ciência da Informação e Gestão da informação. São Luiz, 2011. Disponível em: <http://rabci.org/rabci/node/231> Acesso em: 10 set. 2015. 